\title{
Direitos autorais e acesso à cultura
}

Allan Rocha de Souza*

Resumo O presente trabalho encara os problemas relativos ao conteúdo e relevância do direito de acesso à cultura, suas relações com os direitos autorais e seus efeitos sobre os limites da proteção. Na reflexão proposta são destacadas a relevância e importância do direito de acesso à cultura por meio de uma análise interdisciplinar e apresentadas as normas jurídicas e fatos sociais que regulam e informam tanto os direitos culturais - em particular o acesso - como os direitos autorais. Ao final conclui-se pela existência de elementos sociais e instrumentos jurídicos para uma efetiva concretização do direito de acesso à cultura, e pela necessidade de uma mudança na forma como são concebidas, interpretadas e aplicadas as normas jurídicas em questão.

Palavras-chave direitos culturais; acesso à cultura; direitos autorais; função social.

\section{Copyright and rights of access to culture}

\begin{abstract}
The present work faces problems related to the content and importance of the right of access to culture, the relations with copyright law and the effects over copyright limitations. The article highlights the relevance and importance of the right of access to culture through an interdisciplinary approach as well as presents the legal norms and social facts that regulate and inform both cultural rights - access in particular - and copyright. At the end, the conclusion points to the existence of social elements and legal instruments for the effective realization of the right of access to culture, and of the need for change on the conception, interpretations and application of the legal norms in question.
\end{abstract}

Keywords cultural rights; access to culture; copyright; social function.

\section{Introdução}

\footnotetext{
* Doutor em Direito Civil pela Universidade do Estado do Rio de Janeiro (UERJ). Professor e pesquisador do curso de Direito do Intituto Três Rios da Universidade Federal Rural do Rio de Janeiro (UFRRJ). Professor e Pesquisador do Programa de Pós-Graduação em Políticas Públicas, Estratégias e Desenvolvimento (PPED) da Universidade Federal do Rio de Janeiro (UFRJ)
}

Liinc em Revista, v.7, n.2, setembro, 2011, Rio de Janeiro, p. 416- 436 - http://www.ibict.br/liinc 
Cultura é um fenômeno que incide sobre todas as atividades humanas, enquanto o Direito é uma ciência social que se propõe, além de promover transformações, a normatizar as relações sociais, evitando o surgimento e escalonamento de conflitos em potencial, precipuamente para proteção da pessoa humana. O elemento cultural perpassa as todas as relações sociais, inclusive as jurídicas e, sendo assim, o Direito deve ser compreendido como reflexo da cultura de grupos espacial e temporalmente localizados.

As artes também refletem os sentimentos e visões de mundo de seus criadores e intérpretes. Seu entendimento busca principalmente localizá-las no contexto das demais expressões humanas, incorporá-las na textura de um universo simbólico particular, atribuindo-lhes um significado cultural. Os possíveis sentidos das artes são socialmente construídos e tanto sua produção como apreciação são dependentes do conjunto de experiências culturais vivenciadas tanto pelos artistas como pelo público. As artes são, enfim, expressões artístico-culturais.

A partir da segunda metade do século XX, o próprio fenômeno cultural, como intermediador das relações humanas, passa a ser também compreendido como objeto do Direito. Isto é resultado da emergente necessidade dos povos de proteger suas particularidades contra a percebida ameaça de uniformização cultural. Seus contornos e efeitos sobre o ordenamento jurídico começam a ser compreendidos e os direitos autorais, particularmente, sofrem a influência da normatividade transformada pelos direitos culturais.

O presente trabalho encara os problemas relativos ao conteúdo dos direitos culturais e põe em destaque o direito de acesso, suas relações com os direitos autorais e seus efeitos sobre os limites da proteção.

\section{Cultura e os direitos culturais}

Os sentidos comuns da palavra "cultura", ainda que insuficientes para as demandas e limites deste trabalho, permitem revelar as fortes associações entre os seus sentidos históricos e contemporâneos, seus significados derivados e as relações de produção, circulação e usos de arte. Igualmente importantes são as remissões à identidade e história de coletividades específicas que o termo impõe, uma vez que indivíduos e grupos são compreendidos como possuidores de certos marcadores de distintividade ou afinidade em razão das suas práticas culturais. Assim, é sempre importante sinalizar que "cultura" é um termo aglutinador que, ao juntar tantas atividades e atributos em um só conjunto, de fato pode confundir ou ocultar distinções que deveriam ser feitas (THOMPSON, 1998, p. 26).

A construção dos conceitos científicos, antropológicos, de cultura, ao também sofrerem as influências das circunstâncias históricas, passou por diversos desafios, teóricos e práticos, até o presente. Diversas áreas acadêmicas trabalham com os conceitos de cultura e as discordâncias sobre os principais elementos e conteúdo deste fenômeno ultrapassam as demarcações dos campos específicos. Mas, para permitir o diálogo produtivo, faz-se necessário uma concordância conceitual mínima quanto aos seus principais aspectos. 
A partir das diversas contribuições, uma nova síntese pode ser então vislumbrada. Não que qualquer das questões clássicas (materialista e idealista, universalista e particularista, etc.) tenha se esvaziado ${ }^{1}$, mas um consenso mínimo, integrando posições de umas e de outras, foi alcançado. E é possível perceber uma convergência entre os sentidos gerais antropológicos e sociológicos de cultura como modo de vida global pautado por um sistema de significações, essencial e envolvido em todas as formas de atividade social.

Nesta perspectiva consensual, a ordem cultural encontra-se em uma relação dinâmica com as demais ordens sociais, na medida em que são ao mesmo tempo constitutivas e constituídas por estas, não mais como uma ou outra. Cultura é assim encarada como um sistema de significações mediante o qual uma dada ordem social é comunicada, reproduzida, vivenciada, e transformada.

Em seu sentido mais especializado - ainda que mais comum - o entendimento de cultura como conjunto de atividades artísticas e intelectuais, que são partes de um sistema mais amplo de significações, estende-se para abranger todas as práticas significativas - como a linguagem, a moda, a publicidade, etc. -, para além das expressões e formas de produção intelectual tradicionais (RAYMOND, 2008, p. 13).

Clifford Geertz ${ }^{2}$, na esteira de Max Weber, ao descrever o homem como um animal suspenso em teias de significância construídas por eles mesmos, e assumir que cultura é o conjunto destas teias, indica que sua análise não deve ser de uma ciência experimental em busca de leis gerais, mas uma interpretativa na procura de sentidos para a vida ${ }^{3 .}$ Desta maneira, o autor avança o entendimento do fenômeno cultural imprimindo uma característica conceitual, em que cultura é a estrutura dos sentidos, idéias e significados que uma determinada visão de mundo contém ${ }^{4}$, e o objetivo do estudioso do tema é revelar esta estrutura simbólica e, para tal, deve, através do processo hermenêutico - equivalente à história, literatura, filosofia -, buscar interpretativamente construir os modos de pensamento e expressão dos membros daquele grupo ou comunidade (GEERTZ, 1974).

Entre as características marcantes do fenômeno, este mesmo autor indica que cultura é pública, porque significados o são; é ideacional, mas não se localiza nas mentes individualmente, por ser relacional; é imaterial, embora não seja oculta, estando refletida em todas as práticas sociais (GEERTZ, 1974, p.10). No trabalho de campo, o etnógrafo encontra uma multiplicidade de estruturas conceituais, muitas sobrepostas e interligadas umas às outras, que deve apreender para expor (GEERTZ, 1974, p.10). Visto deste modo, cultura não é um poder, ao qual ações,

\footnotetext{
${ }^{1}$ É de grande relevância a descrição e a crítica aos paradigmas materialistas, ao buscar compreendê-la no que lhe é mais caro - a prevalência do econômico e político sobre as demais searas da vida - como fenômeno cultural de conteúdo simbólico oferecida em SAHLINS, 1976, em especial, o Capítulo 4.

${ }^{2}$ As discussões sobre cultura são parte integral dos estudos das ciências sociais e, consequentemente, são muitas as visões particulares que, por mais valiosas que sejam, escapam aos objetivos deste trabalho, para cujos fins faz-se necessário apontar os principais paradigmas que pautam as discussões e indicar os pressupostos conceituais sobre o qual serão trabalhadas as questões posteriores. E dentre as diversas elaborações sobre cultura, a expressão marcante de seu conteúdo, conforme entendido contemporaneamente, vem, para os fins aqui dispostos, de Clifford Geertz.

${ }^{3}$ Nas palavras do autor: "believing, with Max Weber, that man is an animal suspended in webs of significance he himself has spun, I take culture to be those webs, and the analysis of it to be therefore not an experimental science in search of law but an interpretative one in search of meaning." (GEERTZ, 1973, p. 5).

${ }^{4}$ Neste debate, Geertz aponta que, para conhecer a estrutura cultural de qualquer crença ou prática, deve-se: "first of all, conceptualize it historically and with other beliefs of this type. Then you can discuss the incidence of it, how people got it, how they got rid of it, and what determined all these things. But, what the cultural element is. It is the structure of meanings, ideas or significances that that particular ideology contained." (SHWEDER, 1984 p. 8).
}

Liinc em Revista, v.7, n.2, setembro, 2011, Rio de Janeiro, p. 416- 436 - http://www.ibict.br/liinc 
comportamentos, processos ou instituições se submetem, mas um contexto no qual estas podem ser descritas (GEERTZ, 1974, p.14).

O Direito não é um campo imune às influências culturais, mas as relações entre cultura e direito são demasiadamente amplas para que seja possível extenuá-las ou mesmo aprofundá-las nos limites deste trabalho. Contudo, merecem, dentre estas relações, ser destacadas as influências culturais na formação, aplicação, interpretação e efetividade das normas jurídicas. A consciência dos efeitos do elemento cultural sobre o Direito impõe a sua renovação e superação dos pressupostos que insistem na possibilidade de legitimidade desvinculada do contexto sóciocultural local.

A continuidade histórica dos conceitos legais é um "postulado básico do pensamento legal do Ocidente desde o Iluminismo, quando o racionalismo criou a utopia de um sistema legal baseado em axiomas racionais desenvolvidos com o apoio da matemática" (HESPANHA, 2001, p. 149). Esta perspectiva tende a obscurecer o sistema de valores por trás das normas jurídicas, que deriva da percepção de que "esses paradigmas resultam de um raciocínio legal eterno, e não de universos de crenças esculpidos pela cultura"(HESPANHA, 2001, p. 149). A necessária recuperação, no plano da teoria legal, da percepção das diferenças históricas e culturais, traz a visão da localidade dos valores sociais implícitos nas normas jurídicas (HESPANHA, 2001, p. $150)$.

Deste modo, é possível ver o Direito igualmente como força de estabilidade e de mudança, na medida em que "se destina à salvaguarda e à garantia de valores realizados, assim como à realização ordenada de novos valores"(REALE, 1977, p. 265). O fenômeno jurídico, assim analisado, apresenta-se "como um processo que se desenvolve na dimensão da historicidade e no qual se articulam as normas - momento culminante deste processo -, os fatos que estão na sua origem e os valores ou fins que constituem sua razão de ser" (MARTINS-COSTA; BRANCO, 2002, p. 174).

Estas colocações ficam ainda mais claras ao observar-se que, ainda quando fundadas em tratados internacionais, a conformação das normas jurídicas são sempre decisões locais - sejam dos legisladores, aplicadores ou destinatários - e, por isso mesmo, "toda ordem jurídica é também expressão de uma forma de vida em particular, e não apenas o espelhamento do teor universal (destas normas)" (HABERMAS, 2004).

O estudo da cultura do Direito pode então ser entendido como uma análise dos valores sociais, necessariamente culturais e históricos, conforme refletido nas normas, em sua interpretação e aplicação em um dado ordenamento jurídico. ${ }^{5}$ Em comparação com o exame do direito enquanto

\footnotetext{
${ }^{5}$ Neste sentido, Orlando Gomes, (2006, p. 19-20)) fala da cultura do Código Civil de 1916, e aponta que "Na organização jurídica (de seus institutos) o Código Civil sofre a influência marcante dos costumes próprios dessa sociedade subdesenvolvida. [...] Mas, por outro lado, distancia-se da realidade, avançando o sinal, para haurir, na doutrina e na legislação de povos mais adiantados, concepções e disposições próprias do grau de seu desenvolvimento. [...] As condições de vida do país, tão distantes daquelas em que tais construções se levantaram, reagiram sobre o próprio pensamento desta elite progressista, e exerceriam marcada influência sobre as instituições e o modo por meio do qual o Direito seria aplicado". Sobre o Código Civil de 1916, ver também PONTES DE MIRANDA (1982, p. 489), quando afirma que o Código Civil "condensa um direito mais preocupado com o círculo social da família do que com os círculos sociais da nação”. Sobre os fundamentos sociais do Código Civil de 2002, Miguel Reale, em História do Novo Código Civil, refere-se à alteração dos valores imbuídos na estrutura do novo instrumento no que diz respeito à diretriz para "alteração geral do código atual no que se refere a certos valores considerados essenciais, tais como os de eticidade, sociabilidade e operabilidade", sendo os dois primeiros
} 
expressão cultural e social, a análise do que seja um direito da cultura altera o foco da investigação, passando do estudo dos fundamentos sócio-culturais do Direito para concentrar-se na cultura como objeto do Direito.

A historicamente recente apropriação legal do elemento cultural como objeto do próprio direito é reflexo das mudanças histórico-culturais do campo jurídico, e sua consolidação normativa acaba por assegurar aos indivíduos e grupos a possibilidade de exigir judicialmente a participação, respeito e liberdade culturais.

Embora formalmente instituídas, as normas jurídicas que estabelecem os direitos culturais ainda carecem de melhor compreensão e maior aplicação. E parece ser justamente esta carência no entendimento de seu conteúdo e efeitos, aliada à postura conservadora - de resistência ao novo de muitos atores do sistema jurídico, que retardam a plena concretização dos direitos culturais. E neste ponto, a questão deixa de ser meramente jurídica para se tornar política, em seu sentido mais amplo.

\section{Artes, acesso e promoção cultural}

A estreita associação entre as artes e cultura vem do surgimento desta última palavra no sentido alemão dado à kultur, pois a legitimação dos grupos burgueses médios alemães, círculo social onde se cunhou este significado, consistia essencialmente em suas realizações intelectuais, artísticas ou científicas (ELIAS,1994a, p. 28).

Os sentimentos e sentidos de vida que os povos e pessoas têm são refletidos em diversas áreas da existência e os diálogos sobre a arte objetivam primordialmente localizá-la no contexto das demais expressões humanas. ${ }^{6}$ As discussões e definiç̧ões de arte jamais são totalmente sobre sua esteticidade, mas principalmente sobre sua contextualização, sua incorporação na textura de um modo de vida particular, e tem por objetivo a atribuição aos artefatos artísticos de um significado cultural (GEERTZ, 1983, p. 97).

O estudo das formas artísticas é a exploração de seus sentidos, cuja formação é essencialmente coletiva e profundamente sustentada na própria existência social. Esta percepção afasta o observador da análise puramente estética da arte e o aproxima da compreensão de que os trabalhos artísticos são "mecanismos elaborados para definição das relações sociais, sustentação das normas sociais e fortalecimento dos valores sociais"(GEERTZ, 1983, p. 99). A relação entre as artes e a vida coletiva não é instrumental, mas semiótica, pois materializam uma visão particular no mundo dos objetos. São documentos primários da vida social, concepções para as

especialmente afeitos aos valores culturais da sociedade contemporânea (São Paulo: Revista dos Tribunais, 2005). Por fim, para uma ampla análise da diversidade dos ordenamentos jurídicos contemporâneos Cf. DAVID, 2002.

${ }^{6}$ Em suas próprias palavras: "...the feeling a people has for life appears, of course, in many other places than in their art. It appears in their religion, their morality, their science, their commerce, their technology, their politics, their amusements, their law, even in the way they organize their everyday political experience. The talk about art that is not merely technical or a spiritualization of the technical - that is, most of it - is largely directed to placing it within the context of these other expressions of human purpose and the pattern of experience they collectively sustain." (GEERTZ, 1983, p. 96). 
quais as pessoas buscam atribuir sentido dentro do conjunto de outros documentos igualmente primários (GEERTZ, 1983, p. 99-100), na medida em que tanto refletem quanto impactam o conjunto de significados da ordem social onde se inserem.

As obras artísticas são significativas porque conectadas com os sentidos que elas mesmas ajudam a criar $^{7}$ Assim, independentemente das capacidades inatas, biológicas, de estímulo sensível, as respostas que suscitam estão atreladas aos sentidos mais amplos da vida social, que resultam das interações entre os membros do grupo (GEERTZ, 1983, p. 102). Refletem ainda as visões de mundo dos criadores, como aponta Henri Matisse quando afirma que "eu sou incapaz de distinguir entre os sentimentos que tenho pela vida e a minha forma de expressá-lo", ou seja, "os meios de uma arte e o sentimento pela vida que os anima são inseparáveis" (GEERTZ, 1983, p. 98)

A capacidade de perceber os significados de uma obra de arte é, como a competência para produzi-la, produto resultante da experiência coletiva. É da "participação no sistema geral de formas simbólicas - que chamamos de cultura - que a participação no sistema particular que chamamos de arte é possível (GEERTZ, 1983, p. 108-109). O próprio senso estético é um produto cultural. $\mathrm{O}$ artista trabalha com as possibilidades de sua audiência perceber o seu trabalho e estas habilidades são desenvolvidas através da experiência de viver entre as coisas para ver, ouvir, ler, pensar, lidar, reagir. Os equipamentos sócio-culturais para produzir e absorver os sentidos das artes têm a mesma origem (GEERTZ, 1983, p. 118). As artes são sensíveis aos tipos de interpretação que a mente as traz, e seus sentidos possíveis são socialmente construídos.

Então, pode-se preliminarmente concluir que as expressões artísticas refletem as atitudes e entendimento da vida por parte dos criadores e também que a percepção, apreensão e atribuição dos sentidos a estes artefatos pelo público estão calcadas em sua inserção no universo simbólico que moderam as interpretações, que por sua vez dependem de sua exposição não só aos artefatos, mas igualmente ao conjunto significativo que pauta a produção e compreensão destas obras. $\mathrm{Na}$ medida em que as visões de mundo e sentidos da vida são resultantes das construções simbólicas elaboradas a partir das interações sociais, a exposição às obras artísticas é condição para participação na construção deste universo, dos significados destas obras e para a sua produção.

Não é difícil vislumbrar, a partir desses pressupostos, que as condições sociais, que possibilitam e limitam as experiências individuais, estão diretamente ligadas às expressões criativas. A arte é, portanto, socialmente condicionada. ${ }^{9} \mathrm{O}$ significado das experiências coletivas para o desenvolvimento dos artistas e de sua obra só pode ser percebido a partir tanto da descrição das estruturas da sociedade de sua época, principalmente com relação às diferenças de poder, como

\footnotetext{
${ }^{7} \mathrm{O}$ autor afirma que: "(artistic objects) are meaningful because they connect to a sensibility they join in creating." (GEERTZ, 1983, p. 101)

${ }^{8}$ Nas palavras do autor: "The purpose of a painter must not be conceived as separated from his pictorial means, and these pictorial means must be more completed (I do not mean more complicated) the deeper his thought. I am unable to distinguish between the feeling I have for life and my way of expressing it." MATISSE, Henri. Apud Id. Ibid., p. 96.

${ }^{9}$ Clássico exemplo deste tipo de análise pode ser encontrado em ELIAS (1994b), ao analisar Mozart e sua obra.
} 
de seus destinos pessoais. ${ }^{10}$ Só assim é possível entender as coerções que agem sobre o artista e suas reações a elas. ${ }^{11}$

Como elemento envolvido pelas teias de significado, socialmente constituídas e constituintes, desde a sua concepção até sua apreensão, passando pela produção, circulação e acesso, as obras de arte, e, principalmente, o gosto por elas, são artifícios de distinção social, sendo efetivos marcadores de classe, uma vez que "a obra de arte só adquire sentido e só tem interesse para quem é dotado do código segundo o qual ela é codificada" (BOURDIEU, 2008, p. 10).

Contrapondo-se à visão naturalizada de que a apreciação estética é um dom intrínseco, a pesquisa científica indica que as práticas culturais, as preferências por tipos de arte e, dentro do mesmo tipo, as opções por determinados estilos "estão estritamente relacionadas ao nível de instrução e, secundariamente, à origem social” (BOURDIEU, 2008, p. 9). Há uma nítida correlação entre a "hierarquia socialmente reconhecida das artes" e a hierarquia social de seus consumidores. É justamente isso que predispõe os gostos a funcionarem como "marcadores privilegiados de "classe" (BOURDIEU, 2008, p. 9). As distinções operadas entre o belo e o feio, o distinto e o vulgar, o merecedor de apreço ou de desprezo qualificam aqueles que classificam as formas de arte, pois exprimem ou traduzem sua condição social, seja adquirida ou de origem (BOURDIEU, 2008, p. 13).

Como as definições da competência cultural são resultantes das condições de sua aquisição, "funcionam como uma espécie de 'marca de origem' e contribuem (ainda) para definir o valor de seus produtos em diferentes mercados" (BOURDIEU, 2008, p. 64). O valor econômico atribuído a certas obras ou experiências artísticas - que aumenta na medida em que são apreciados pelas classes abastadas - colaboram para sua utilização enquanto elemento distintivo.

A condição cultural expressa no gosto pelas artes é a fonte destas divisões, pois, de fato, "a consagração cultural submete os objetos, pessoas e situações que ela toca a uma espécie de promoção ontológica que se assemelha a uma transubstanciação" (BOURDIEU, 2008, p. 14).

Esses entendimentos permitem concluir que a prática e o gosto pela arte, seja como usuário ou criador, são atividades como qualquer outra, socialmente aprendidas e culturalmente localizadas, temporal e espacialmente, prestando também o campo artístico às funções de hierarquização e distinção social.

E é justamente em razão do seu papel distintivo e legitimador das hierarquias sociais que as restrições ao acesso devem ser sopesadas, de maneira a reduzir os seus efeitos sociais negativos e, ao mesmo tempo, incrementar os benefícios do amplo acesso.

A importância do elemento cultural na formação das experiências, valores e identidade dos indivíduos é patente. Constituída e vivenciada a partir das relações sociais dos indivíduos, o

\footnotetext{
${ }^{10}$ No tempo de Mozart, "no que se referia à música, ainda se tinha como certo que o artista devia seguir o gosto da audiência, socialmente superior. A estrutura de poder que dava a nobreza de corte precedência sobre todas as outras classes também determinava que tipo de música um artista burguês poderia tocar nos círculos cortesãos e até que ponto suas inovações poderiam ir. Mesmo como 'artista autônomo', Mozart estava preso a tal estrutura." (ELIAS, 1994, p. 41).

${ }^{11}$ No caso específico de Mozart e seu tempo, "o gosto da nobreza da corte estabelecia o padrão para os artistas de todas as origens sociais, acompanhando a distribuição geral de poder." Igualmente os conflitos entre sociais entre a aristocracia decadente e a burguesia ascendente "ocorria também no interior de muitos indivíduos como um conflito que perpassava toda a existência social”. (ELIAS, p. 16, 17, 19).
}

Liinc em Revista, v.7, n.2, setembro, 2011, Rio de Janeiro, p. 416- 436 - http://www.ibict.br/liinc 
aparato simbólico em que se constitui a cultura é fator essencial à formação das visões de mundo de pessoas e grupos. São vários os comportamentos, ideias e artefatos que convêm significados, permitem a atribuição de sentido e formam o contexto onde se desenvolvem as pessoas.

É desse entendimento da cultura como aparato simbólico que permite atribuir sentido às ações, comportamentos, relações, práticas, artefatos e à própria vida, pautando a existência e as experiências individuais, conformando as identidades individuais e coletivas, que partem as análises deste trabalho.

As expressões artísticas são artefatos privilegiados enquanto objetos culturais, dotados de forte conteúdo simbólico. Assegurar o acesso amplo e desembaraçado a estas obras é garantir a liberdade no desenvolvimento das identidades culturais, individuais e coletivas, é propiciar as condições para a promoção da inclusão, cidadania e democracia culturais e é, ainda, o melhor instrumento para fomentar um círculo virtuoso da economia criativa.

\section{Os direitos culturais no ordenamento jurídico}

Há no ordenamento jurídico nacional explicita referência legislativa tanto aos direitos culturais como aos direitos autorais.

Dentre os dispositivos constitucionais, os que se referem diretamente à cultura são os artigos 23, 24 e 30, dispondo sobre competências; $5^{\circ}$, inc. IX e 220, ao tratar da liberdade de expressão e de sua comunicação; $5^{\circ}$, inc. XXVII e XXVIII, ao constituir direitos autorais patrimoniais, conceder titularidade originária ao autor, atribuir exclusividade temporária na exploração econômica e assegurar a fiscalização das obras artísticas; 206, inc. II, apontando para a sua relação com o ensino; $5^{\circ}$, inc. LXXIII, ao assegurar a legitimidade para propor ação popular para anular ato lesivo ao patrimônio histórico; 215 e 216, circunscrevendo o objeto dos direitos culturais; 221 e, em certa medida, 222, refletindo sua importância na comunicação de massa; 227, como um direito fundamental da criança e do adolescente; 231, na proteção das expressões culturais dos grupos indígenas e do espaço onde se realizam. ${ }^{12}$

\footnotetext{
${ }^{12}$ José Afonso da Silva (2001, p. 42) afirma o seguinte: “A Constituição Brasileira de 1988 refere-se à cultura nos arts. $5^{\circ}$, IX, XXVII, XXVIII e LXXIII, e $220, \S \S 2^{\circ}$ e $3^{\circ}$, como manifestação do direito individual e de liberdade e direitos autorais; nos arts. 23, 24 e 30, como regras de distribuição de competência e como objeto de proteção pela ação popular; nos arts. 215 e 216, como objeto do direito e patrimônio brasileiro; no art. 219, como incentivo ao mercado interno, de modo a viabilizar o desenvolvimento cultural; no art. 221, como princípios a serem atendidos na produção e programação das emissoras de rádio e televisão; no art. 227, como um direito da criança e do adolescente; e no art. 231, quando reconhece aos índios asua organização social, costumes, línguas, crenças e tradições e quando fala em terras tradicionalmente ocupadas por eles, necessárias à reprodução física e cultural, segundo seus usos, costumes e tradições.”
}

Liinc em Revista, v.7, n.2, setembro, 2011, Rio de Janeiro, p. 416- 436 - http://www.ibict.br/liinc 
Dentre estes, para as finalidades deste trabalho, merecem destaque os artigos $215^{13}$ e $216^{14}$ da Constituição Federal são decisivos na conformação do ordenamento constitucional da cultura, pois normatizam os objetos principais dos direitos culturais e o art. $5^{\circ}$, inc. XXVII e XXVIII, que tratam dos direitos autorais.

As normas do direito da cultura encontram-se igualmente positivadas nos principais tratados internacionais de direitos fundamentais, que recebem apreço especial no ordenamento jurídico nacional ${ }^{15}$, por força dos $\S 2^{0}{ }^{16}$ e $3^{0}{ }^{17}$ do art. $5^{\circ}$ da Constituição Federal ${ }^{18}$, cuja aplicação é imediata por conta de seu $\S 1^{\circ}{ }^{\circ}{ }^{19}$

Dentre os tratados internacionais de direitos fundamentais ratificados pelo Brasil e de aplicação direta às questões aqui abordadas, destacam-se a Declaração Universal dos Direitos do Homem

\footnotetext{
${ }^{13}$ Art. 215. O Estado garantirá a todos o pleno exercício dos direitos culturais e acesso às fontes da cultura nacional, e apoiará e incentivará a valorização e a difusão das manifestações culturais. $\S 1^{\circ}-\mathrm{O}$ Estado protegerá as manifestações das culturas populares, indígenas e afro-brasileiras, e das de outros grupos participantes do processo civilizatório nacional. $\S 2^{\circ}$ - A lei disporá sobre a fixação de datas comemorativas de alta significação para os diferentes segmentos étnicos nacionais. $\S 3^{\circ}$ A lei estabelecerá o Plano Nacional de Cultura, de duração plurianual, visando ao desenvolvimento cultural do País e à integração das ações do poder público que conduzem à: I defesa e valorização do patrimônio cultural brasileiro; II produção, promoção e difusão de bens culturais; III formação de pessoal qualificado para a gestão da cultura em suas múltiplas dimensões; IV democratização do acesso aos bens de cultura; V valorização da diversidade étnica e regional.

14 Art. 216. Constituem patrimônio cultural brasileiro os bens de natureza material e imaterial, tomados individualmente ou em conjunto, portadores de referência à identidade, à ação, à memória dos diferentes grupos formadores da sociedade brasileira, nos quais se incluem: I - as formas de expressão; II - os modos de criar, fazer e viver; III - as criações científicas, artísticas e tecnológicas; IV - as obras, objetos, documentos, edificações e demais espaços destinados às manifestações artístico-culturais; V - os conjuntos urbanos e sítios de valor histórico, paisagístico, artístico, arqueológico, paleontológico, ecológico e científico. $\S 1^{\mathrm{o}}$ - O Poder Público, com a colaboração da comunidade, promoverá e protegerá o patrimônio cultural brasileiro, por meio de inventários, registros, vigilância, tombamento e desapropriação, e de outras formas de acautelamento e preservação. $\S 2^{\circ}$ Cabem à administração pública, na forma da lei, a gestão da documentação governamental e as providências para franquear sua consulta a quantos dela necessitem. $\S 3^{\circ}$ - A lei estabelecerá incentivos para a produção e o conhecimento de bens e valores culturais. $\S 4^{\circ}$ - Os danos e ameaças ao patrimônio cultural serão punidos, na forma da lei. $\S 5^{\circ}$ - Ficam tombados todos os documentos e os sítios detentores de reminiscências históricas dos antigos quilombos. $\S 6^{\circ}$ É facultado aos Estados e ao Distrito Federal vincular a fundo estadual de fomento à cultura até cinco décimos por cento de sua receita tributária líquida, para o financiamento de programas e projetos culturais, vedada a aplicação desses recursos no pagamento de: I - despesas com pessoal e encargos sociais; II - serviço da dívida; III - qualquer outra despesa corrente não vinculada diretamente aos investimentos ou ações apoiados.

${ }^{15}$ É importante ressaltar a relevância do depoimento prestado pelo jurista Antônio Augusto Cançado Trindade na audiência pública na subcomissão dos direitos e garantias individuais, cuja acolhida das sugestões resultou na abertura constitucional privilegiada aos preceitos dos tratados internacionais de direitos fundamentais, estabelecida no $\S 2^{\circ}$ do art. $5^{\circ}$ da Constituição Federal. Ver detalhes em ASSEMBLÉIA NACIONAL CONSTITUINTE - Atas das Comissões. Vol. 1, n. 66, 27-05-87, pp. 108-116.

16 “Os direitos e garantias expressos nesta Constituição não excluem outros decorrentes do regime e dos princípios por ela adotados, ou dos tratados internacionais em que a República Federativa do Brasil seja parte"

17 "Os tratados e convenções internacionais sobre direitos humanos que forem aprovados, em cada Casa do Congresso Nacional, em dois turnos, por três quintos dos votos dos respectivos membros, serão equivalentes às emendas constitucionais."

${ }^{18} \mathrm{O} \S 3^{\circ}$ e $\S 4^{\circ}$ do artigo $5^{\circ}$ foram acrescidos por força da Emenda Constitucional 45 de 2004.

19 "As normas definidoras dos direitos e garantias fundamentais têm aplicação imediata"
}

Liinc em Revista, v.7, n.2, setembro, 2011, Rio de Janeiro, p. 416- 436 - http://www.ibict.br/liinc 
${ }^{20}$, o Pacto dos Direitos Civis e Políticos ${ }^{21}$ - e seu Protocolo Facultativo ${ }^{22}$, o Pacto dos Direitos Econômicos, Sociais e Culturais ${ }^{23}$, o Pacto de São José da Costa Rica ${ }^{24}$ e o Protocolo Adicional 25.

Especificamente sobre os direitos culturais, há diversos tratados internacionais lidando com o assunto sob diferentes enfoques. Dentre estes se destacam ${ }^{26}$, para fins deste trabalho, a Convenção Relativa às Medidas a Serem Adotadas para Proibir e Impedir a Importação, Exportação e Transferência de Propriedades Ilícitas sobre Bens Culturais ${ }^{27}$, a Convenção para Proteção do Patrimônio Mundial, Natural e Cultural $^{28}$, a Convenção para Salvaguarda do Patrimônio Cultural Imaterial ${ }^{29}$, a Declaração Universal sobre Diversidade Cultural $^{30}$ e a Convenção para Promoção e Proteção da Diversidade Cultural. ${ }^{31}$

A Declaração Universal dos Direitos Humano ${ }^{32}$, fonte primária ${ }^{33}$ dos direitos fundamentais no plano internacional ${ }^{34}$, aborda no mesmo artigo tanto o direito à proteção às criações artísticas

\footnotetext{
${ }^{20}$ Durante os anos de 1947 e 1948 diversas decisões tomadas a partir da primeira sessão regular da Comissão de Direitos Humanos da ONU, em fevereiro de 1947, que resultaram na Declaração Universal de Direitos Humanos, adotada e proclamada na Assembleia Geral das Nações Unidas em 10 de dezembro de 1948. O plano geral era de constituição de uma Carta Internacional de Direitos Humanos, do qual a Declaração seria a sua primeira parte, que posteriormente seriam completadas por uma ou duas convenções e medidas de implementação. As medidas de implementação não constavam na Declaração, que contudo versava significativamente tanto sobre os direitos civis e políticos - arts. $2^{\circ}$ a 21 - quanto os direitos econômicos, sociais e culturais - arts. 22-28. Ver CANÇADO TRINDADE, 1998, p. 24-25.

${ }^{21}$ O Pacto dos Direitos Civis e Políticos foi adotado pela Assembleia Geral, em 16 de dezembro de 1966, por 106 votos a zero.

${ }^{22}$ O Protocolo Facultativo não constava inicialmente nos planos da Carta Internacional de Direitos Humanos, mas foi elaborado a partir da necessidade de garantir efetividade às medidas adotadas, de implementação direta pois dependiam apenas de uma abstenção do Estado. Este Protocolo foi aprovado por 66 votos a favor, 2 contra e 38 abstenções, na Assembleia Geral de 16 de dezembro de 1966.

${ }^{23}$ O Pacto dos Direitos Econômicos, Sociais e Culturais foi adotado pela Assembleia Geral em 16 de dezembro de 1966 por 105 votos a zero.

${ }^{24}$ Este instrumento foi adotado na Conferência Especializada Interamericana sobre Direitos Humanos, realizada em 1969, justamente em San José, Costa Rica.

${ }^{25}$ O Brasil aderiu a este Tratado em 08 de agosto de 1996, tendo depositado a Adesão em 21 de agosto de 1996. Disponível em: < http://www.oas.org/juridico/spanish/tratados/a-52.html >. Acesso em 10 out. 2009.

${ }^{26}$ Estes tratados e convenções são apontados pela UNESCO como sendo os principais instrumentos internacionais sobre cultura. Disponível em: $\leq$ www.brasilia.unesco.org/publicacoes/docinternacionais/doccultura $>$. Acesso em: 28 out. 2009.

${ }^{27}$ Concluída em Paris em14 de novembro de 1970. Aprovada pelo Decreto Legislativo n. 71, 1972.

${ }^{28}$ Concluída em Paris em 16 de novembro de 1972. O Brasil depositou sua Aceitação na UNESCO em 01 de setembro de 1977.

${ }^{29}$ Concluída em Paris em 17 de outubro de 2003. Ratificada pelo Brasil pelo Decreto n. 5.753, de 12 de abril de 2006.

${ }^{30}$ Aprovada na $31^{\text {a }}$ Conferência Geral da UNESCO, em Paris, em 02 de novembro de 2001, sendo assinada por 185 países, inclusive o Brasil.

${ }^{31}$ Concluída em Paris em 20 de outubro de 2005, foi ratificada pelo Brasil pelo Decreto Lei n. 6.177, agosto de 2007.

${ }^{32}$ Aprovada e Proclamada pela Resolução 217 A (III) da Assembleia Geral das Nações Unidas em 10 de dezembro de 1948.

${ }^{33}$ Com a posterior adoção dos Pactos de Direitos Civis e Políticos e de Direitos Econômicos, Sociais e Culturais, somados à Declaração Universal de 1948, completava-se o plano inicial de constituição da Carta Internacional de Direitos Humanos. Ver CANÇADO TRINDADE, 1998, p. 28.

${ }^{34}$ Embora reconhecida sua influência nas constituições modernas e nos ordenamentos jurídicos nacionais, persiste o debate sobre sua eficácia nos países que a ratificaram. Debate-se principalmente se é uma norma direcionada exclusivamente aos Estados ou se é suficiente para constituir direitos exigíveis imediatamente pelos cidadãos. Obviamente devem ser consideradas as particularidades dos ordenamentos nacionais no que diz respeito à
}

Liinc em Revista, v.7, n.2, setembro, 2011, Rio de Janeiro, p. 416- 436 - http://www.ibict.br/liinc 
quanto o direito de participação cultural e fruição das artes, impondo sua conjunção e prevendo, assim, a conjunção entre estes dois interesses. ${ }^{35}$ Esta Declaração foi complementada por dois Pactos firmados em 1966, o Pacto dos Direitos Civis e Políticos e o Pacto dos Direitos Econômicos, Sociais e Culturais.

O principal aspecto tratado no Pacto dos Direitos Civis e Políticos ${ }^{36}$ foi o direito a não discriminação na atribuição e exercício dos direitos ${ }^{37}$, para o qual devem ser assegurados instrumentos jurídicos de efetivação. ${ }^{38}$ São especialmente afirmados os direitos à vida ${ }^{39}$, à ampla liberdade ${ }^{40}$, ao reconhecimento de sua personalidade ${ }^{41}$ e a submissão ao princípio da legalidade. 42

O Pacto dos Direitos Econômicos, Sociais e Culturais ${ }^{43}$, em seu preâmbulo, após reconhecer que os direitos sociais derivam da dignidade humana, afirma que o ideal de um homem livre não pode ser realizado sem que seja possível concretizar os direitos econômicos, sociais e culturais, bem como os civis e políticos. Acrescenta ainda que todos, sem isenção, devem contribuir para a concretização destes direitos e da própria dignidade. Estes direitos sustentam-se no dever jurídico da solidariedade, que tem como fundamento ético a concepção de justiça distributiva (COMPARATO, 2004, p. 64.) Este instrumento igualmente aponta os limites da restrição ao exercício destes direitos sociais e a essencialidade dos direitos fundamentais à educação ${ }^{44} \mathrm{e}$ cultura ${ }^{45}$ para completude da dignidade e do próprio exercício da liberdade.

qualificação interna dos tratados internacionais de direitos humanos. Também devem ser considerados o fato de serem Declarações, Recomendações ou Convenções, Pactos e Tratados. As Declarações e Recomendações não são exigíveis do Estado, mas os Tratados, Pactos ou Convenções são. Esta distinção foi um dos aspectos relevantes ressaltados por Cançado Trindade na Audiência pública na Subcomissão de Direitos e Garantias Individuais da Assembleia Constituinte quando questionado sobre a inclusão das Declarações internacionais do qual o país é parte como fonte de direitos e garantias individuais, razão pela qual sugeriu a inclusão do termo Tratado junto com a declaração. Em suas próprias palavras: "As declarações de que o Brasil é signatário têm efeito puramente recomendatório. Se amanhã surge um problema em nosso país se invoca uma Declaração das Nações Unidas, poder-se-á objetar: mas ela não tem efeito mandatório. Por isso, vou um pouco além da Comissão de Estudos Constitucionais e sugiro: além das declarações de que o país é signatário também os tratados de que o país é parte." Ao final, optou-se por fazer referências aos tratados como fonte de direitos fundamentais, além do regime e princípios adotados pela própria constituição. Cf. Id. Ibid., 169-170.

${ }^{35}$ 27.1.: Todo o homem tem o direito de participar livremente da vida cultural da comunidade, de fruir as artes e de participar do progresso científico e de fruir de seus benefícios. 27.2.: Todo o homem tem direito à proteção dos interesses morais e materiais decorrentes de qualquer produção científica, literária ou artística da qual seja autor.

${ }^{36}$ Ratificado no Brasil pelo Decreto 592, de 06 de julho de 1992.

${ }^{37}$ Art $2^{\circ}, 1$.

${ }^{38}$ Art. $2^{\circ}, 3$.

${ }^{39}$ Ainda que não vedando a pena de morte, restringe-o ao afirmar, em seu art. $6^{\circ}, 1$, que "o direito à vida é inerente à pessoa humana. Este direito deverá ser protegido pela lei. Ninguém poderá ser arbitrariamente privado de sua vida." ${ }^{40}$ Art. $9^{\circ}, 1$.

${ }^{41}$ Art. 16.

${ }^{42}$ Art. 14: 1 .

${ }^{43}$ Ratificado pelo Dec. 591, em 06 de julho de 1992.

${ }^{44}$ Art. 13: Os Estados Partes do presente Pacto reconhecem o direito de toda pessoa à educação. Concordam em que a educação deverá visar o pleno desenvolvimento da personalidade humana e do sentido de sua dignidade e fortalecer o respeito pelos direitos humanos e liberdades fundamentais. Concordam ainda em que a educação deverá capacitar todas as pessoas a participar efetivamente de uma sociedade livre, favorecer a compreensão, a tolerância e a amizade entre todas as nações e entre todos os grupos raciais, étnicos ou religiosos e promover as atividades das Nações Unidas em prol da manutenção da paz.

${ }^{45}$ Art. 15: 1. Os Estados Partes do presente Pacto reconhecem a cada indivíduo o direito de: a) Participar da vida cultural; b) desfrutar o progresso científico e suas aplicações; c) beneficiar-se da proteção dos interesses morais e materiais decorrentes de toda a produção científica, literária ou artística de que seja autor. 2. As medidas que os Estados Partes do presente Pacto deverão adotar com a finalidade de assegurar o pleno exercício desse direito

Liinc em Revista, v.7, n.2, setembro, 2011, Rio de Janeiro, p. 416- 436 - http://www.ibict.br/liinc 
Conforme estabelecidos no Pacto, os direitos culturais são interdependentes e fortemente relacionados aos outros direitos fundamentais sociais, bem como a certos direitos civis e políticos. Em termos gerais, se relacionam a uma variedade de aspectos do direito à educação, à participação na vida social, à comunicação e à informação. Porém, em seu aspecto mais particular, têm forte impacto na possibilidade de proteção da criação e comunicação destas obras por parte dos artistas e, ao mesmo tempo, na garantia de acesso do público a tais obras como forma de participação na vida cultural, o que, por sua vez, afeta a construção das identidades culturais dos povos. ${ }^{46}$

O conteúdo dos direitos culturais no Brasil está, portanto, estruturado a partir de quatro diretrizes normativas, que são: (1) a livre e plena participação na vida cultural da comunidade; (2) o acesso às fontes e fruição dos bens de cultura nacional; (3) o incentivo às diversas manifestações culturais e a proteção das identidades; (4) e o robustecimento do patrimônio cultural brasileiro.

Os direitos culturais também fundamentam, influenciam, iluminam, legitimam, albergam e confirmam outros direitos em nosso ordenamento. Neste caso, sua influência não deixa de ser sentida, mas concorre com outros preceitos na formação dos contornos destes, variando sua influência conforme o caso. São alimentados pelos direitos culturais, por exemplo, a liberdade de expressão, os direitos autorais, o direito à comunicação e a proibição da discriminação. São direitos culturais lato sensu, na medida em que a revelação de seus conteúdos é influenciada pelo conteúdo dos direitos culturais stricto sensu.

O direito de acesso á cultura tem destacada importância, pois as possibilidades e formas de acesso condicionam os próprios direitos culturais, afetando sua realização e amplitude. $\mathrm{O}$ acesso é, portanto, a condição indispensável para a concretização de quaisquer dos direitos culturais, mormente o de participação.

Ao mesmo tempo, não é possível pensar em acesso sem o correspondente direito de fruição destes bens e vivência das experiências. O conteúdo do direito de acesso é também informado pelo disposto nos tratados internacionais, que preveem a fruição dos bens culturais como um dos direitos culturais. Ainda que assim não fosse, acesso sem a possibilidade de fruição é preceito vazio, inócuo, inoperante, contrário à lógica da substancialidade das normativas constitucionais. Acesso e fruição cultural são conceitos vinculados e implicam-se mutuamente, pois refletem as mesmas finalidades, que é permitir a participação e exercício destes direitos.

Sem acesso, não é possível a inclusão, emancipação, cidadania, democracia ou desenvolvimento culturais, nem a formação, criação, manifestação, produção ou expressão culturais, que somente são viáveis com acesso e fruição dos bens culturais. Assim, da perspectiva dos direitos culturais, a exceção jurídica é a restrição ao acesso, porque afeta negativamente a participação e o próprio exercício dos direitos culturais.

Os efeitos do desequilíbrio de acesso - seja em relação aos bens culturais ou à informação - são negativos para a própria liberdade, dignidade e cidadania, pois "quanto menos a informação,

aquelas necessárias à conservação, ao desenvolvimento e à difusão da ciência e da cultura. 3. Os Estados Partes do presente Pacto comprometem-se a respeitar a liberdade indispensável à pesquisa científica e à atividade criadora. 4 . Os Estados Partes do presente Pacto reconhecem os benefícios que derivam do fomento e do desenvolvimento da cooperação e das relações internacionais no domínio da ciência e da cultura.

${ }^{46}$ KARTASHKIN, Vladimir. Economic, social and cultural rights. In: VASAK, Karel. The international dimensions of human rights. Paris: Unesco, 1982, p. 127.

Liinc em Revista, v.7, n.2, setembro, 2011, Rio de Janeiro, p. 416- 436 - http://www.ibict.br/liinc 
menor a possibilidade de liberdade que o ser humano tem, e, portanto, menor dignidade em relação ao outro, criando cidadanias diferentes" ${ }^{47}$.

O direito de acesso é a porta de entrada para o exercício dos demais direitos culturais e condição sine qua non para a inclusão, democracia e cidadania culturais.

\section{Acesso à cultura e direitos autorais}

A partir dos dispositivos normativos vigentes é forçoso concluir que tanto o direito de acesso à cultura como os direitos autorais estão igualmente protegidos como direitos fundamentais. Se houver alguma supremacia de um sobre o outro é no sentido de ser o direito de acesso preponderante sobre os direitos autorais. Contudo, nos casos em que ambos direitos constituídos incidem sobre as circunstâncias e conjuntamente delineiam o confronto, a questão é mais bem colocada no sentido de promover a integração entre ambos e não a exclusão de algum deles.

A proteção dos espaços materiais e imateriais de interação e manifestação culturais é conseqüência inafastável da ampla proteção da pessoa humana em todas as suas dimensões, cuja sustentação judicial positivada se encontra no estabelecimento da dignidade humana como um dos fundamentos da República. ${ }^{48}$

E é somente a partir da consideração dos seus efeitos sobre a existência pessoal, a formação das identidades, a construção da cidadania, interações sociais e diálogo livre, o alcance do desenvolvimento cultural, com uma interpretação jurídica sistemática e teleológica direcionada à plena satisfação das normas estabelecidas na Constituição, nos tratados internacionais e na regulamentação infraconstitucional, que o conteúdo dos direitos culturais pode ser revelado e os seus efeitos sobre os direitos sobre os direitos patrimoniais autorais podem ser indicados.

$\mathrm{Na}$ condução deste processo não é possível olvidar que os direitos autorais são justificados e funcionalizados em razão dos direitos culturais desde o seu surgimento histórico. ${ }^{49}$ Sua justificativa atual é complementada pelo elemento pessoal que assegura a manutenção do vínculo entre autor e obra, com algumas outras consequências desta ordem. ${ }^{50} \mathrm{O}$ próprio vínculo pessoal

\footnotetext{
${ }^{47}$ BRASIL. Supremo Tribunal Federal. Aditamento do voto da Min. Carmen Lúcia na Argüição de Descumprimento de Preceito Fundamental n. 130-DF. Tribunal Pleno. Relatora: Min. Carlos Britto, Brasília, 30 de abril de 2009, p. 97. Disponível em: <www.stj.gov.br>. Acesso em: 25 out. 2009.

${ }^{48}$ Conforme positivado no art. $1^{\circ}$, III, CRFB/1988.

${ }^{49}$ No título do Estatuto da Rainha Ana, primeira legislação que concedia aos autores o direito original sobre suas obras lia-se "An Act for the Encouragement of Learning, by vesting the Copies of Printed Books in the Authors or purchasers of such Copies, during the Times therein mentioned." A Constituição Americana, no artigo $1^{\circ}$, seção $8^{\mathrm{a}}$, cláusula $8^{\mathrm{a}}$, afirma que o Congresso tem poder de legislar "to promote the progresso f science and useful arts, by securing for limited times to authors and inventors the exclusive right to their respective writings and discoveries."

${ }^{50}$ Processo histórico de reconhecimento dos direitos morais do autor ocorreu durante a segunda metade do século XIX, tendo sido tópico de grande debate na Convenção de Berna de 1908, e incluído na Convenção de Berna em 1928. Para um excelente e clássico estudo sobre o tema ver STRONHOLM, Sting. Le Droit Moral de L'Auteur en Droit Allemand, Français et Scandinave. V. 2., Stochholm: P.A. Norstedt \& Soners Forlag, 1967. Para uma análise contemporânea ver ADENEY, Elizabeth. The moral rights of authors and performers - an international and comparative analysis. Nova York: Oxford University Press, 2006.
}

Liinc em Revista, v.7, n.2, setembro, 2011, Rio de Janeiro, p. 416- 436 - http://www.ibict.br/liinc 
de paternidade tem uma função cultural pública, pois permite a identificação do autor de determinada obra $^{51}$, enriquecendo o conjunto de referências culturais e auxiliando na compreensão do contexto sócio-histórico-cultural da manifestação, também relevante do ponto de vista da memória.

Os direitos patrimoniais do autor e, em alguns casos, os direitos morais ${ }^{52}$ restringem o acesso e a própria liberdade de criação e manifestação. Esta restrição, contudo, é justificada pelo suposto incentivo à produção cultural, com consequências positivas para a formação do patrimônio cultural brasileiro. A inserção dos direitos autorais entre os direitos fundamentais legitima esta exceção ao acesso plenamente livre e irrestrito às obras artístico-culturais.

Isso não implica em dizer que esta exclusividade de uso seja ilimitada ou absoluta. Jamais o foi, pois estes direitos já surgiram limitados, no tempo e no alcance. As limitações aos direitos autorais são legitimadas por outros direitos fundamentais, inclusive os direitos culturais, com especial atenção ao direito de acesso à cultura. O cerceamento jurídico ao direito de acesso e à liberdade de criação e manifestação não pode ultrapassar os limites da razoabilidade e deve, por excepcional, ser interpretado restritivamente.

Na perspectiva dos direitos culturais, a exclusividade de usos é uma exceção ao direito de acesso à cultura, justificada como um incentivo econômico à criação ${ }^{53}$ É em razão dos direitos culturais - uma vez que o incentivo à criação tem por fito o engrandecimento cultural da sociedade - que os autores são constitucionalmente elevados a uma categoria especial de trabalhadores, o que, per se, demonstra ser, de fato, uma exceção.

É também espúria a restrição injustificada ou excessiva ao acesso na medida em que ofende os princípios democráticos, pois permite o autoritarismo cultural dos titulares dos bens de acesso restrito. A restrição do acesso provoca a escassez artificial destes bens e possibilita inclusive a constitucionalmente condenável censura de mercado. ${ }^{54}$

\footnotetext{
${ }^{51}$ Neste sentido ver FOUCAULT, Michael. O que é um autor?. In: Manoel Barros da Motta (Org.). Ditos e Escritos III - Estética: Literatura e Pintura, Música e Cinema, p. 264-298.

${ }^{52}$ Especificamente prejudicial à liberdade de criação e manifestação são os direitos de integridade e modificação, quando a interpretação atribui extensão exagerada ao seu conteúdo.

${ }_{53}$ Uma análise econômica da propriedade intelectual mostra que, por serem os bens sujeitos à propriedade intelectual não-rivais, sua escassez só ocorrerá se for artificialmente estabelecida, que é o que fazem as leis de propriedade intelectual, inclusive de direitos autorais.

${ }^{54}$ Um exemplo de uso das normas de direitos autorais para a vedação da circulação de obras, sob a questionável justificativa de infração à exclusividade de uso, é a obra "Além de Cidadão Kane" (Beyond Citizen Kane). Concluído em 1992, produzido por John Ellis e dirigido por Simon Hartog, o documentário foi transmitido pela primeira vez em 1993, no Canal 4 britânico. O tema do filme é a concentração e a manipulação da mídia no Brasil, e tem como foco Roberto Marinho, a Rede Globo e suas relações com o Poder. A promiscuidade destas relações no Brasil mostrada no filme remonta ao período de ditadura militar, inclui uma série de entrevistas e utiliza diversos trechos da programação da Rede Globo como ilustração de suas críticas. O uso destas imagens é visto como um empecilho à transmissão televisiva do filme, embora tenha sido exibido publicamente no Brasil em diversas ocasiões, com autorização e segundo informações do Produtor. A ameaça de ação judicial é o elemento inibidor, em razão dos custos envolvidos, ainda que a legislação permita a utilização de trechos de obras para fins de polêmica e crítica, assim como a lei britânica, sob a qual foi feito o filme. Matérias jornalísticas publicadas pela Folha de São Paulo ilustram a polêmica, estando disponíveis em: $<\underline{\text { http://www1.folha.uol.com.br/folha/brasil/ult96u375398.shtml }>} \quad$ e $<$ http://www1.folha.uol.com.br/folha/ilustrada/ult90u612350.shtml $>$. Acessos em: 16 fev. 2010. O filme encontra-se disponível na íntegra no Google Vídeos no endereço <http://video.google.com/videoplay?docid=570340003958234038\#>. Acesso em 16 fev. 2010.
}

Liinc em Revista, v.7, n.2, setembro, 2011, Rio de Janeiro, p. 416- 436 - http://www.ibict.br/liinc 
O aparente conflito entre a liberdade de acesso e sua restrição deve ser resolvido em favor da liberdade, como indica o Supremo Tribunal Federal ao afirmar que "quando se tem um conflito possível entre a liberdade e a restrição, deve-se defender a liberdade". ${ }^{55}$

Deste modo, é importante observar que as influências dos direitos culturais sobre os direitos autorais são múltiplas, justificando, em confluência com outras disposições, tanto a proteção patrimonial, como a proteção pessoal quanto às limitações à exclusividade. Os direitos autorais estão, de fato, embebidos nos direitos culturais.

A ponderação entre o direito de acesso à cultura e os direitos patrimoniais de autor é necessária para solucionar aparentes conflitos. O direito fundamental de acesso à cultura somente pode sofrer restrições que não se contraponham às suas finalidades, nem configurem um retrocesso em sua aplicação, como já exposto. Por outro lado, as limitações impostas aos direitos autorais devem ser condizentes com a "regra dos três passos". Qualquer solução deve considerar estes marcos jurídicos, que limitam as restrições a qualquer destes direitos.

A legislação de direitos autorais regula interesses diversos, de cunho tanto individual como coletivo. Os aspectos individuais alcançam não só os pessoais e patrimoniais do autor, mas também os estritamente econômicos ligados ao investimento. Os coletivos compreendem os relevantes direitos da sociedade incidentes sobre a obra protegida, como, por exemplo, a educação, cultura e informação. ${ }^{56}$

Neste grupo merecem especial destaque os interesses do criador e do público, pois são alicerçados nos direitos fundamentais. E, por isso, sobrepõem-se àqueles exclusivamente econômicos dos investidores. Esta condição de supremacia dos direitos fundamentais é constitucionalmente imposta e deve ser respeitada em todas as interpretações e aplicações da legislação ordinária, por todos os poderes públicos e pessoas de direito privado. ${ }^{57}$

Duas perguntas principais derivam desta situação. A primeira questiona quais, dentre os interesses particulares do autor, merecem proteção e quais os meios adequados para se efetivar a proteção. A segunda indaga quais usos livres são necessários à satisfação dos interesses coletivos. Destas questões decorrem as dúvidas centrais quanto aos direitos autorais: qual é o ponto de equilíbrio entre a proteção do criador do investimento e entre os direitos patrimoniais do titular e os direitos do público. Esta última refere-se às limitações dos direitos patrimoniais do autor, aspecto nevrálgico para a sua conformação frente ao direito de acesso à cultura.

Atualmente convergem para o debate dos limites dos direitos autorais as discussões a respeito dos efeitos desta proteção sobre a educação, a liberdade de expressão artística, a inclusão dos portadores de necessidades especiais, a privacidade e também com relação ao exercício dos direitos culturais, dentre outros. Assim, esta questão encontra-se na ordem do dia em diversos contextos nacionais e internacionais e não é exclusiva do Brasil.

\footnotetext{
${ }^{55}$ BRASIL. Supremo Tribunal Federal. Argüição de Descumprimento de Preceito Fundamental n. 130-DF. Tribunal Pleno. Relator: Min. Carlos Brito, Brasília, 30 de abril de 2009, p. 91. Disponível em: <www.stj.gov.br>. Acesso em: 10 nov. 2009.

${ }^{56}$ Este assunto foi mais profundamente explorado em SOUZA, 2009, p. 17-36.

${ }^{57}$ Este foi o conteúdo principal da apresentação em Audiência Pública na Comissão de Educação e Cultura da Câmara Federal dos Deputados, em 11 nov. 2008. SOUZA, 2008.
}

Liinc em Revista, v.7, n.2, setembro, 2011, Rio de Janeiro, p. 416- 436 - http://www.ibict.br/liinc 
Os tribunais brasileiros já deram mostra de que, apesar do aguerrido lobby judicial - direto e indireto - dos titulares de direitos autorais, podem enfrentar satisfatoriamente o problema, levando em consideração o interesse público primário, que é afetado negativamente pela excessiva extensão dos direitos patrimoniais de autor.

Ilustrativamente, o Supremo Tribunal Federal, no Recurso Extraordinário n. 113.505-1 58, julgado em 28 de fevereiro de 1989, reconhece a relevância da finalidade do uso na definição do alcance das normas que estabelecem limites á proteção autoral.

Em seu voto, o relator Moreira Alves - coincidentemente redator da Lei 5.988/73 - apontou, citando Wistrand, que no direito de autor as exceções se apresentam como consequência de sua natureza social, sendo restringidos no interesse da coletividade, seja por regras expressas seja por exceções inerentes ao seu conteúdo. Cita José de Oliveira Ascensão, que afirma que "o texto legal, não impede, já hoje, uma interpretação extensiva." Menciona, ainda, Pontes de Miranda, que já admitia interpretação extensiva do art. 666 do Código Civil de 1916, que tratava dos limites dos direitos autorais. Justifica também a interpretação extensiva como forma de adequação da legislação às transformações sociais, no caso, tecnológicas. Ao final, o relator conclui pela interpretação extensiva dos limites estabelecidos na legislação. ${ }^{59}$

Esta decisão, formidavelmente esquecida pelos defensores da interpretação restritiva, aponta os caminhos do entendimento equilibrado dos limites. Esclarece o vínculo dos limites com os interesses da coletividade e, a partir de sua fundamentação, no que acompanha outras decisões, funcionaliza a compreensão destes limites. Corrobora, portanto, com a vigência da interpretação extensiva dos limites aos direitos autorais.

Recentemente, o Superior Tribunal de Justiça, em decisão relacionada à lei 9.610/98, enfrentou o problema da interpretação dos limites dos direitos autorais. Ao analisar o Recurso Especial 964.404, a Corte decidiu pela "Necessidade de interpretação sistemática e teleológica do enunciado normativo do art. 46 da Lei n. 961098 à luz das limitações estabelecidas pela própria lei especial" de maneira que se assegure a "tutela de direitos fundamentais e princípios constitucionais em colisão com os direitos do autor, como a intimidade, a vida privada, a cultura, a educação e a religião." 60

A decisão, paradigmática, define ainda que "o âmbito efetivo de proteção do direito à propriedade autoral (art. $5^{\circ}, \mathrm{XXVII}$, da CF) surge somente após a consideração das restrições e limitações a ele opostas", limitações estas que resultam "do rol exemplificativo extraído dos enunciados dos artigos 46, 47 e 48 da Lei 9.61098, interpretadas e aplicadas de acordo com os direitos fundamentais." 61

Estas decisões revelam claramente que a interpretação dos limites dos direitos autorais é - e sempre foi - extensiva, pois as limitações expressas na legislação especial são meramente

\footnotetext{
${ }^{58}$ BRASIL. Supremo Tribunal Federal. Recurso Extraordinário n. 113.505-RJ. Primeira Turma. Relator: Min. Moreira Alves, Brasília, 28 de fevereiro de 1989. Disponível em: <www.stf.jus.br>. Acesso em 30 ago. 2011.

59 BRASIL. Supremo Tribunal Federal. Recurso Extraordinário n. 113.505-RJ. Primeira Turma. Relator: Min. Moreira Alves, Brasília, 28 de fevereiro de 1989. Disponível em: <www.stf.jus.br>. Acesso em 30 ago. 2011.

${ }^{60}$ BRASIL. Superior Tribunal de Justiça. Recurso Especial n. 964.404. Terceira Turma. Relator: Paulo de Tarso Sanseverino, Brasília, 15 de março de 2011. Disponível em: <www.stj.jus.br>. Acesso em 30 ago. 2011.

${ }^{61}$ BRASIL. Superior Tribunal de Justiça. Recurso Especial n. 964.404. Terceira Turma. Relator: Paulo de Tarso Sanseverino, Brasília, 15 de março de 2011. Disponível em: <www.stj.jus.br>. Acesso em 30 ago. 2011.
} 
exemplificativas. Os fundamentos das limitações são os direitos fundamentais, que também sustentam a própria proteção autoral. As limitações não são exceções e refletem a composição necessária entre direitos de igual estatura potencialmente em conflito.

O alcance das limitações aos direitos autorais é restringido internacionalmente pela "regra dos três passos". Porém, entre os exemplos na legislação e a restrição imposta internacionalmente às limitações aos direitos autorais, há bastante espaço para alargamento do rol exemplificativo, seja legislativamente seja judicialmente.

Há, portanto, sustentação jurídica para a demanda sócio-política de constituição de espaços onde a circulação, criação e fruição dos bens artístico-culturais sejam livres e plenas, onde o acesso à cultura e os demais direitos culturais se impõem. Estes espaços de livre circulação cultural conformam os locais nos quais criadores e público são cultivados, tornando-se os alicerces de uma sociedade criativa e culturalmente densa.

\section{Considerações finais}

As restrições à fruição dos bens culturais são causas da desigualdade e exclusão culturais, afetando a dignidade humana, o exercício da cidadania e o fortalecimento da democracia e, por estas consequências, o cerceamento do acesso ofende os objetivos e fundamentos republicanos expostos em nossa carta magna. Portanto, qualquer restrição ao acesso tem de ser ao mesmo tempo legitimada, em razão da ponderação com outros direitos fundamentais, e, ao mesmo tempo, não causar nenhum dos desequilíbrios sociais apontados.

A concretização dos direitos culturais demanda a existência de espaços culturais públicos e instrumentalizados para a participação plena e livre na vida cultural. Esta instrumentalização inclui a implantação de condições materiais e imateriais, dentre as quais a existência de espaços físicos e equipamentos técnicos que viabilizem as expressões e manifestações, o conhecimento dos modos de criar, fazer e comunicar e as condições jurídicas e econômicas que permitam esta participação e exercício qualificados.

Os espaços culturais livres, onde as manifestações culturais são incondicionadas, são o manancial das culturas, e sua minimização sufoca o dinamismo cultural e retira o alimento que as sustentam, que são as próprias interações culturais livres, incondicionadas e espontâneas. Resguardá-los, protegê-los e ampliá-los deve ser prioritário na progressiva implantação dos direitos culturais no Brasil, com todas as suas consequências.

Como fundamentais que são, os direitos culturais, entre outras coisas, exigem ações positivas. Os deveres prestacionais advêm das normas constitucionais e impõem obrigações ao Estado de legislar, construindo o arcabouço jurídico do direito da cultura e viabilizando o exercício positivo do direito à cultura. Assim, "o papel do poder público deve ser de favorecer a livre procura das manifestações culturais, criar condições de acesso popular à cultura, prover meios para que a difusão cultural se fundamente nos critérios de igualdade" (SILVA, 2001, p. 48) . Portanto, "a ação cultural do Estado há de ser ação afirmativa que busque realizar a igualização 
dos socialmente desiguais, para que todos, igualmente, aufiram os benefícios da cultura" SILVA, 2001, p. 49). Estes direitos impõem também um dever específico, principalmente ao Judiciário, de interpretar as normas jurídicas infraconstitucionais a partir do conteúdo dos direitos fundamentais culturais.

Estes deveres representam os direitos culturais do cidadão, a quem cabe decidir, se quer ou não, participar do processo de significação, de construção dos significados e sentidos sociais dos bens culturais. Em razão disto, a todos cabe o dever de abstenção, de não cercear o exercício dos direitos culturais ou restringir injustificadamente o direito de acesso à cultura. As obrigações de não fazer, constituídas pelos direitos de defesa em que os direitos culturais implicam, são direcionadas tanto ao Estado como aos entes privados.

Os instrumentos jurídicos para o verdadeiro reconhecimento e concretização dos direitos culturais estão à disposição dos operadores ou agentes do direito, independentemente de seus papéis, quer sejam advogados, defensores, promotores, procuradores, magistrados ou juristas.

As escolhas dos agentes do Direito diante de conflitos que opõem o direito de acesso à cultura e os direitos autorais não são estritamente fundadas na técnica jurídica - como se pode crer e fazer crer - mas em opções políticas dos atores envolvidos. A seleção dos dispositivos e dos fatos sociais considerados relevantes, a análise dos efeitos de determinada posição ou decisão, as soluções encontradas e suas justificativas, são influenciados e condicionados pela visão de mundo e formação cultural dos agentes e são, portanto, culturalmente condicionadas. O pleno reconhecimento e concretização dos direitos culturais dependem, acima de tudo, de uma reformulação intelectual de alcance cultural do próprio campo jurídico.

E diante do contexto contemporâneo internacional, onde o diferencial está cada vez mais nos conteúdos simbólicos e culturais, nem os poderes constituídos nem a sociedade podem prescindir desta transformação. Para tal, será preciso uma mudança cultural no Direito que reconheça o valor e importância dos direitos culturais e do acesso á cultura.

Artigo recebido em 22/06/11 e aprovado em 12/07/11.

\section{Referências}

ADENEY, Elizabeth. The moral rights of authors and performers - an international and comparative analysis. Nova York: Oxford University Press, 2006. 
ASSEMBLÉIA NACIONAL CONSTITUINTE - Atas das Comissões. Vol. 1, n. 66, 27-05-87, pp. 108-116.

BAUMAN, Zygmunt. Liquid modernity. Cambridge: Polity Press, 2000.

BOBBIO, Norberto. Da estrutura à função: novos estudos de teoria do direito. Trad. Daniela Beccaccia Versiani; revisão técnica: Orlando Seixas Bechara e Renato Nagamine. Barueri, SP: Manole, 2007.

BOURDIEU, Pierre. A distinção: crítica social do julgamento. São Paulo: EDUSP, 2008.

CANÇADO TRINDADE, Antônio Augusto. A proteção internacional dos direitos humanos no Brasil. Brasília: Editora Universidade de Brasília, 1998.

COMPARATO, Fábio Konder. A afirmação histórica dos direitos humanos. 4. ed., Rio de Janeiro: Saraiva, 2004.

DAVID, René. Os grandes sistemas do direito contemporâneo. São Paulo: Martins Fontes, 2002.

DAVIES, Gillian. Copyright and the public interest. Londres: Sweet \& Maxwell, 2002.

DEWEY, John. Liberalismo, liberdade e cultura. São Paulo: Editora Nacional, 1970.

ECO, Umberto. Obra aberta - forma e indeterminações nas poéticas contemporâneas. São Paulo: Perspectiva, 2008.

ELIAS, Norberto. O processo civilizador. Rio de Janeiro: Jorge Zahar Editora, 1994a.

ELIAS, Norbert. Mozart: sociologia de um gênio. Rio de Janeiro: Jorge Zahar Editor, 1994b.

FOULCAULT, Michael. O que é um autor?. In: Manoel Barros da Motta (Org.). Ditos e Escritos III - Estética: Literatura e Pintura, Música e Cinema. Rio de Janeiro: Forense Universitária, 2001.

FRANCIONI, Francesco. Culture, heritage and human rights: an introduction. In: FRANCIONI, Francesco; SCHEININ, Martin (Eds.). Cultural Human Rights. Boston: Martinus Nijhoff Publishers, 2008.

GEIGER, Christophe. Constitutionalising intellectual property law? The influence of fundamental rights on intellectual property in the European Union. In: International Review of Intellectual Property and Competition Law, vol. 37, n. 4, Munique, Alemanha: Max Planck Institute for Intellectual Property, Competition and Tax Law, 2006

GEERTZ, Clifford. Art as a cultural system. In: GEERTZ, Clifford. Local Knowledge. New York: Basic Books, 1983. 
GEERTZ, Clifford. "From the native's point of view" - on the nature of anthropological understanding. In: Bulletin of American Academy of Arts and Sciences, Massachusetts, vol. 28, n. $1,1974$.

GEERTZ, Clifford. The interpretation of cultures. USA: Basic Books, 1973.

GOMES, Orlando. Raizes históricas e sociológicas do Código Civil Brasileiro. 2. ed. São Paulo: Martins Fontes, 2006.

HABERMAS, Jungen. A inclusão do outro. 2. ed., São Paulo: Edições Loyola, 2004.

HAUSER, Arnold. História social da arte e da literatura. Porto Alegre: Martins Fontes, 2003.

HESPANHA, Antônio Manuel. A imaginação legal nos primórdios da Era Moderna. In: Novos Estudos, São Paulo, Cebrap, n. 59, mar., 2001.

LEWICKI, Bruno Costa. Limitações aos direitos de autor: releitura na perspectiva do direito civil contemporâneo. 2007. 299 f. Tese (Doutorado em Direito Civil) - Centro de Ciências Sociais, Faculdade de Direito, Universidade do Estado do Rio de Janeiro, Rio de Janeiro.

MARTINS-COSTA, Judith; BRANCO, Gerson. Diretrizes teóricas do novo Código Civil brasileiro. Rio de Janeiro: Saraiva, 2002.

PONTES DE MIRANDA, Fontes e evolução do direito civil brasileiro (Rio de Janeiro: Forense, 1982.

PONTIER, Jean-Marie; RICCI, Jean-Claude; BOURDON, Jacques. Droit de La culture. Paris: Dalloz, 1990.

REALE, Miguel. Horizontes do Direito e da História. 2. ed., Rio de Janeiro: Saraiva, 1977.

RIOU, Alain. Le droit de la culture et le droit à la culture. 2 ed., Paris: ESF Éditeur, 1996.

SAHLINS, Marshall. Culture and pratical reason. Chicago, USA: University of Chicago Press, 1976

SHWEDER, Richard A. Preview: a colloquy of culture theorists. In: SHWEDER, Richard A.; LEVINE, Robert. Culture theory: essays on mind, self and emotion. New York: Cambridge University Press, 1984.

SILVA, José Afonso da. Ordenação constitucional da cultura. São Paulo: Malheiros, 2001.

SILVA, Vasco Pereira. A cultura a que tenho direito. Coimbra: Almedina, 2007.

SOUZA, Allan Rocha de. Direitos Fundamentais, Direitos Autorais e a Busca pelo Equilíbrio. In: Denis Borges Barbosa; Karen Grau-Kuntz (Org.). Ensaios sobre o Direito Imaterial. Rio de Janeiro: Lumen Juris, 2009. 
SOUZA, Allan Rocha. A função social dos direitos autorais. Campos, RJ: Editora da Faculdade de Direito de Campos, 2006.

SOUZA, Allan Rocha. A Proteção Constitucional dos Direitos Autorais. In: Eduardo Salles Pimenta (Org.). Propriedade Intelectual: Estudos em Homenagem ao Ministro Carlos Fernando Mathias de Souza. São Paulo: Letras Jurídicas, 2009, pp. 17-36.

TAMATOPOULOU, Elsa. Cultural rights in international law. Boston: Martinus Nijhoff Publishers, 2008.

THOMPSON, E. P. Costumes em comum. São Paulo: Companhia das Letras, 1998.

VASAK, Karel. The international dimensions of human rights. Paris: Unesco, 1982.

WILLIAMS, Raymond. Cultura. Rio de Janeiro: Paz e Terra, 2008.

ZOLLINGER, Alexandre, Droit d'auteur e droit de l'Homme. França: Université de Poitiers, 2008. 